九州大学学術情報リポジトリ

Kyushu University Institutional Repository

\title{
人工膝関節全置換術における脛骨前縁を骨性指標と して使用した脛骨近位骨切りの精度
}

西川，和孝

https://doi.org/10.15017/4060259

出版情報：Kyushu University，2019，博士（医学），論文博士 バージョン:

権利関係: (C) 2015 Elsevier Inc. All rights reserved. 


\title{
Accuracy of Proximal Tibial Bone Cut Using Anterior Border of Tibia as Bony Landmark in Total Knee Arthroplasty
}

\author{
Kazutaka Nishikawa, MD ${ }^{\text {a }}$, Hideki Mizu-uchi, MD, PhD ${ }^{\mathrm{a}}$, Ken Okazaki, MD, PhD ${ }^{\mathrm{a}}$, Shuichi Matsuda, MD, PhD ${ }^{\mathrm{b}}$, \\ Yasutaka Tashiro, $\mathrm{MD}, \mathrm{PhD}^{\mathrm{a}}$, Yukihide Iwamoto, $\mathrm{MD}, \mathrm{PhD}^{\mathrm{a}}$ \\ a Department of Orthopaedic Surgery, Graduate School of Medical Sciences, Kyushu University, Fukuoka, Japan \\ ${ }^{\mathrm{b}}$ Department of Orthopaedic Surgery, Graduate School of Medical Sciences, Kyoto University, Kyoto, Japan
}

\section{A R T I C L E I N F O}

Article history:

Received 27 February 2015

Accepted 23 June 2015

\section{Keywords:}

total knee arthroplasty

coronal alignment

extramedullary alignment guide

anterior border of tibia

osteoarthritis

\begin{abstract}
A B S T R A C T
The purpose of our study was to evaluate the accuracy of the tibial bone cut in total knee arthroplasty using the anterior tibial border as a guide compared to using bony and soft tissue landmarks of the ankle joint. The extramedullary alignment guide was set parallel to a line connecting the proximal and distal one-thirds of the anterior border of the tibia while the rotational direction of the distal end of the guide was adjusted to the anteroposterior axis of the proximal tibia. Significant differences were detected in the ideal coronal tibial component angles with improvements from $87.2 \%$ to $95.9 \%$. The anterior tibial border was a reliable landmark in total knee arthroplasty in clinical practice, as shown by our previous computer simulation.
\end{abstract}

(c) 2015 Elsevier Inc. All rights reserved.
Total knee arthroplasty (TKA) has become one of the most successful orthopedic procedures for providing pain relief and improving knee function. The rate of TKA failures is decreasing, with reported survival rates of greater than $90 \%$ after 15 years [1,2], however, many factors contribute to the risk of failures that necessitate TKA revision. It is important to position the femoral and tibial components accurately and to balance the soft tissues. Malpositioning of the components can lead to failure due to aseptic loosening, instability, polyethylene wear [3,4], and dislocation of the patella [5]. In particular, the importance of tibial alignment is well recognized. Many papers have recommended that the tibial component be implanted perpendicular to the tibial axis. Placement of the implants within $3^{\circ}$ of the mechanical axis of the lower limb has been proven to reduce wear and early implant failure [6,7]. Berend et al [8] reported that the odds of failure increased up to 17.2 -fold in cases with more than $3^{\circ}$ of varus alignment of the tibial component.

Intramedullary and extramedullary guides are generally used to cut the tibia, and each has both advantages and shortcomings. It is difficult to use intramedullary guides in patients with severe post-fracture

One or more of the authors of this paper have disclosed potential or pertinent conflicts of interest, which may include receipt of payment, either direct or indirect, institutional support, or association with an entity in the biomedical field which may be perceived to have potential conflict of interest with this work. For full disclosure statements refer to http://dx.doi.org/10.1016/j.arth.2015.06.055.

Reprint requests: Hideki Mizu-uchi, MD, PhD, Department of Orthopaedic Surgery, Graduate School of Medical Sciences, Kyushu University, 3-1-1 Maidashi, Higashi-ku, Fukuoka city, Fukuoka, 812-8582, Japan. bowing and deformity [9]. In addition, many studies have reported increased risk of fat embolism with the use of intramedullary guides $[10,11]$. In contrast, extramedullary guides make it easier for surgeons to perform additional checks and to reposition the guides after set-up [12]. However, the use of extramedullary guides necessitates meticulous attention to accurately align the tray during TKA. The position of the distal end is defined subjectively, which can cause incorrect alignment because it is difficult to find the center of the ankle joint, especially in obese patients with an excess of soft tissue and in osteoarthritis patients with abnormal ankle anatomy [13]. The optimal placement within $3^{\circ}$ was reportedly achieved in only $70 \%$ to $80 \%$ of patients when using extramedullary alignment guides, despite improvements in surgical techniques and jigs $[14,15]$.

Several references for aligning extramedullary alignment guides have been reported [16-20]; however, these landmarks have varied widely among papers. It would be ideal to identify a stable landmark so as to allow surgeons to most accurately realize the tibial mechanical axis. We previously performed a three-dimensional computer simulation to evaluate the efficacy of the anterior border of the tibia as a reference for setting extramedullary alignment in TKA [21]. Our computer simulation showed that (1) the line connecting the proximal and distal one-third of the anterior border, and (2) the line connecting the medial one-third of the patellar tendon attachment and the distal one-fourth of the anterior border were similarly parallel to the mechanical axis in the coronal plane. Even though the anterior border of the tibia was reliable as a landmark in the simulation study, its efficacy has not been proven in a clinical setting. The purpose of the present study was to determine whether this method reduced the incidence of tray malalignment when compared to using bony and soft tissue landmarks of the ankle joint. 


\section{Patients and Methods}

Patients

Between January 2007 and September 2013, 513 osteoarthritic knees in 405 Japanese female patients underwent primary TKA. Fiftyeight knees (46 patients) with valgus deformity were excluded because our previous computer simulation included varus knees only, yielding 455 knees (359 patients). Full-length, weight-bearing anteroposterior (AP) radiographs were used to evaluate alignments accurately. We obtained both pre-operative and post-operative radiographs of 341 knees (248 patients). We standardized the implant used, and 191 knees (159 patients) were replaced with the Nexgen Legacy posterior-stabilized prosthesis (Zimmer, Warsaw, Indiana) using an extramedullary guide without computer-assisted navigation. All arthroplasties were performed by one special team for knee surgery at our institution.

We compared the accuracy of component positioning in two groups defined by the surgical technique used to position the distal end of the extramedullary guide. From January 2007 to March 2010, the distal end of the guide was positioned at the ankle center, which was defined based on the surgeon's subjective judgment using bony and soft tissue landmarks (Method A: 117 knees). View direction to the ankle center differed among the surgeons (e.g., there are multiple ways of viewing the ankle center in the direction of the AP axis of the ankle joint). From October 2010 to September 2013, the extramedullary guide was set parallel to a line connecting the proximal and distal one-third of the anterior border (Method B: 74 knees, Fig. 1). The reason for selecting the line was easiness and reproducibility among the surgeons compared to the line connecting the medial one-third of the patellar tendon attachment and the distal one-fourth of the anterior border of the tibia. Procedures during the subsequent 6 months (April 2010 to September 2010) were not included to avoid bias between Methods A and B. This study was approved by the Institutional Review Board and informed consent was obtained from all patients. Preoperative demographic data are shown in Table 1.

\section{Surgical Techniques}

The standard medial parapatellar incision and approach were used. For the distal femur, the intramedullary alignment guide was inserted slightly medial to the midpoint of the femoral condyles. This entry point was determined as the position where the intramedullary line of the femoral canal exited the femoral condyles on the full-length AP
Table 1

The Preoperative Demographic Data.

\begin{tabular}{|c|c|c|}
\hline & Method A $(\mathrm{n}=117)$ & Method B $(\mathrm{n}=74)$ \\
\hline Mean age (years) & $74.4 \pm 7.3(51$ to 87$)$ & $76.8 \pm 7.4(57$ to 91$)$ \\
\hline $\begin{array}{l}\text { Mean hip-knee- } \\
\text { ankle angle }\left(^{\circ}\right)\end{array}$ & $167.2 \pm 5.4(150.4$ to 179.9$)$ & $166.4 \pm 5.7(151.0$ to 179.2$)$ \\
\hline $\begin{array}{l}\text { Mean body mass } \\
\text { index }\left(\mathrm{kg} / \mathrm{m}^{2}\right)\end{array}$ & $26.8 \pm 4.2$ (18.0 to 38.9 ) & $26.6 \pm 4.3(15.6$ to 38.3$)$ \\
\hline $\begin{array}{l}\text { Maximum } \\
\text { extension }\left({ }^{\circ}\right)\end{array}$ & $-7.8 \pm 8.0(-30$ to 5$)$ & $-8.3 \pm 7.0(-20$ to 20$)$ \\
\hline $\begin{array}{l}\text { Maximum flexion } \\
\left({ }^{\circ}\right)\end{array}$ & $118.3 \pm 17.2(70$ to 155$)$ & $118.1 \pm 17.5(75$ to 150$)$ \\
\hline
\end{tabular}

radiographs [22]. The distal femoral cutting block was then attached to the alignment guide, with adjustment for the anatomical valgus angle of the femur. After cutting the distal femur, the cutting block was set parallel to the transepicondylar axis [23]. For cutting the proximal tibia, the extramedullary alignment guide was set at a level approximately $10 \mathrm{~mm}$ distal to the lateral articular surface of the tibia. First, we defined the AP axis that connected the center of the posterior cruciate ligament at the tibial attachment and the medial one-third of the border of the patellar tendon at the tibial attachment. The rotational direction of the proximal side of the guide was adjusted to the AP axis of the proximal tibia marked on the articular surface. All techniques other than setting the distal side of the guide were the same as mentioned above.

In Method A, the distal end of the guide was positioned at the ankle center, which was defined based on the surgeon's subjective judgment using bony and soft tissue landmarks. In Method B, the guide was set parallel to a line connecting the proximal and distal one-third of the anterior border while the rotational direction of the distal end of the guide was adjusted to the AP axis of the proximal tibia (Fig. 2). The planned sagittal alignment of the cutting of the tibia was parallel to the lateral tibial slope [24]. The surgeon was able to check the coronal alignment using the alignment rod with spacer block after cutting the proximal tibia. The rotational alignment of the tibial component was adjusted to the AP axis between the center of the cut surface and the border of the medial one-third of the tibial tuberosity $[25,26]$. The patella was resurfaced in all patients. All femoral, tibial, and patellar components were fixed with cement.

\section{Evaluation of Post-Operative Alignment}

All patients in both groups were evaluated using full-length, weightbearing AP radiographs (Fig. 3). Care was taken to avoid rotational

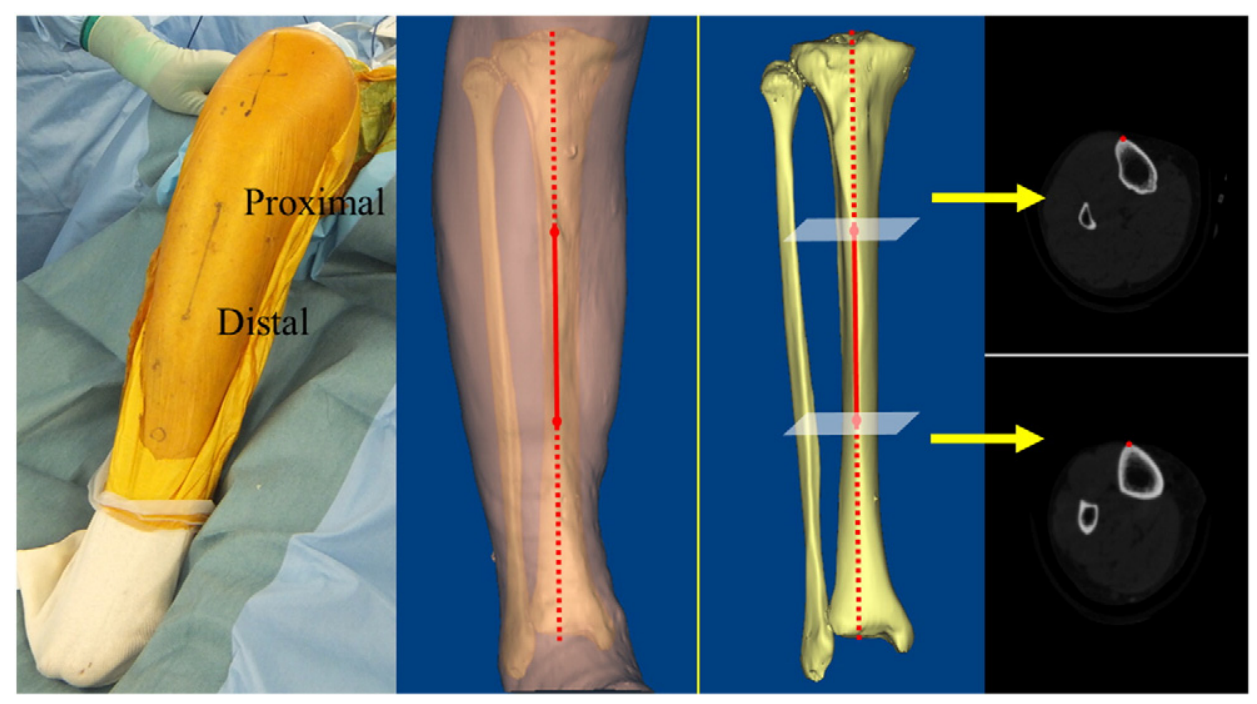

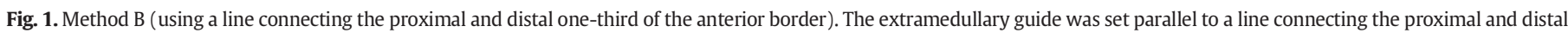
one-third of the anterior border. Solid line: a line connecting the proximal and distal one-third of the anterior border of the tibia. 


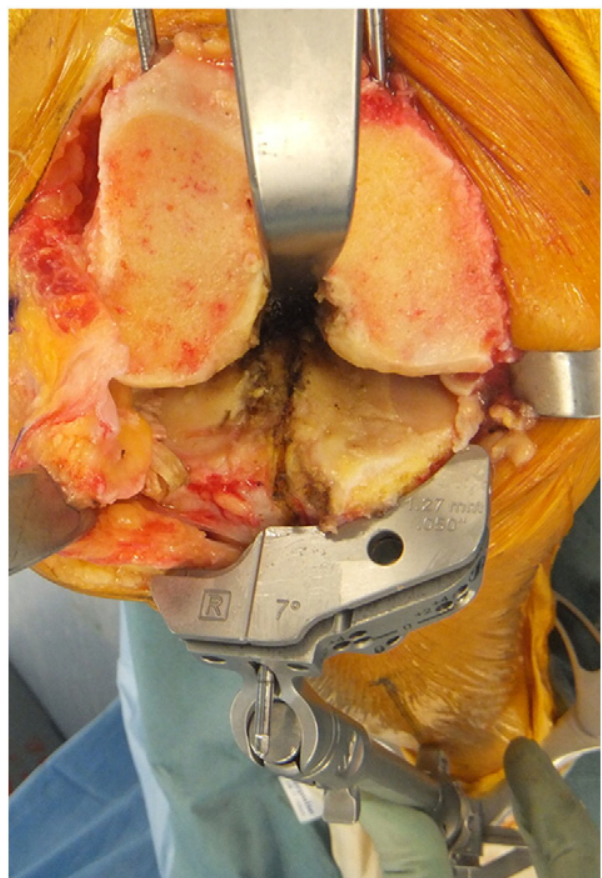

Fig. 2. Anteroposterior axis of the proximal tibia before cutting the proximal tibia. The AP axis was connecting the center of the posterior cruciate ligament (PCL) at the tibial attachment and the medial third border of the patellar tendon at the tibial attachment. The rotational direction of the proximal side of the guide was adjusted to the AP axis of the proximal tibia marked on the articular surface.

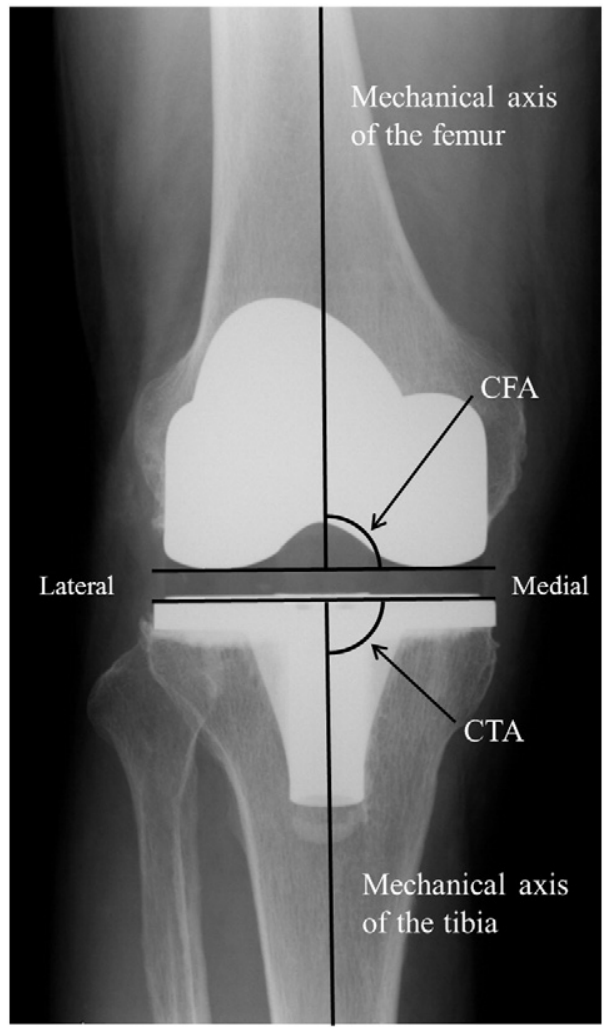

Fig. 3. Evaluation of the coronal alignment of the components. The coronal femoral component angle (CFA) is the medial angle between the mechanical axis of the femur and the horizontal axis of the two prosthetic condyles. The coronal tibial component angle (CTA) is the medial angle between the mechanical axis of the tibia and the horizontal axis of the tibial tray. mismatch between the radiographs and the direction of the tibial components. The mechanical axis of the leg was defined as the hip-kneeankle (HKA) angle, which is the medial angle between the mechanical axis of the femur and the mechanical axis of the tibia. The mechanical axis of the femur was defined as the line connecting the center of the hip with that of the femoral component, and the mechanical axis of the tibia was defined as the line connecting the center of the tibial component with that of the ankle joint. The coronal tibial component angle (CTA) was measured as the medial angle between the mechanical axis of the tibia and the horizontal axis of the tibial tray [22]. The coronal femoral component angle (CFA) was measured as the medial angle between the mechanical axis of the femur and the horizontal axis of the two prosthetic condyles [22]. We considered both angles to be optimal if they were within $3^{\circ}$ of $90^{\circ}$.

\section{Statistical Analysis}

The Mann-Whitney U test was used to determine statistically significant differences $(P<0.05)$ in the absolute values from the target angles obtained by the two methods. Fisher's exact probability test (Chi-square test) was used to compare the quality of implantation, measured against the ideal position, between the two methods $(P<0.05)$. We measured all radiographic data that did not include patient information and that were numbered randomly. The radiograph data were analyzed using a digital measurement software 2D template ${ }^{\circledR}$ (Japan Medical Materials Corp., Osaka, Japan).

\section{Results}

The mean postoperative Knee Society score was $97.0 \pm 4.5$ (70 to 100) for Method A and $97.0 \pm 4.7$ (73 to 100) for Method B. The mean postoperative range of motion was $123.7^{\circ} \pm 18.0^{\circ}$ ( $75^{\circ}$ to $150^{\circ}$ ) for Method $A$ and $120.1^{\circ} \pm 21.5^{\circ}\left(65^{\circ}\right.$ to $160^{\circ}$ ) for Method B. No significant difference was found in these two factors between the methods. The mean CTA was $89.6^{\circ} \pm 1.8^{\circ}\left(85.7^{\circ}\right.$ to $\left.93.8^{\circ}\right)$ for Method $A$ and $89.3^{\circ} \pm 1.6^{\circ}\left(84.5^{\circ}\right.$ to $\left.92.7^{\circ}\right)$ for Method B. The mean CFA was $89.5^{\circ} \pm 2.6^{\circ}\left(82.8^{\circ}\right.$ to $\left.96.3^{\circ}\right)$ for Method $A$ and $88.9^{\circ} \pm 2.4^{\circ}\left(83.4^{\circ}\right.$ to $\left.93.5^{\circ}\right)$ for Method B. The mean HKA angle was $179.3^{\circ} \pm 3.6^{\circ}\left(168.4^{\circ}\right.$ to $\left.187.6^{\circ}\right)$ for Method A and $178.5^{\circ} \pm 3.1^{\circ}\left(171.8^{\circ}\right.$ to $\left.185.5^{\circ}\right)$ for Method B. There were no significant differences between the two groups for any of these mean values. As shown in Table 2, the absolute values from the target angle were not significant for the CTA, CFA, or HKA angle for either group. However, ideal CTA and CFA were obtained in 87.2\% (102 of 117 knees) and 76.1\% (89 of 117 knees) for Method A, and 95.9\% (71 of 74 knees) and 73.0\% (54 of 74 knees) for Method B, respectively. There was a significant difference in ideal CTA between the two groups $(P<0.05)$.

For the three knees with angles beyond $3^{\circ}$ from the target angle in Method $\mathrm{B}$, the average body mass index and preoperative HKA angle were $24.6 \mathrm{~kg} / \mathrm{m}^{2}$ and $159.1^{\circ}$, respectively. For two knees, we were able to perform a computer simulation based on preoperative CT data to evaluate the relationship between a line connecting the proximal and distal one-third of the anterior border and the mechanical axis of the tibia. The discrepancy of one knee relative to the target angle was $0.4^{\circ}$ varus, while that of the other knee was $0.4^{\circ}$ valgus, results that were similar to those of our previous computer simulation study [21].

Table 2

The Differences of Absolute Value from the Target Angle.

\begin{tabular}{lcc}
\hline & Method A & Method B \\
\hline Coronal tibial component angle $\left({ }^{\circ}\right)$ & $1.5 \pm 1.1(0.1$ to 4.4$)$ & $1.4 \pm 1.0(0$ to 5.2$)$ \\
Coronal femoral component angle $\left({ }^{\circ}\right)$ & $2.1 \pm 1.5(0.1$ to 7.3$)$ & $2.1 \pm 1.5(0$ to 6.6$)$ \\
Hip-knee-ankle angle $\left({ }^{\circ}\right)$ & $2.9 \pm 2.1(0$ to 11.6$)$ & $2.8 \pm 2.1(0$ to 8.2$)$ \\
\hline
\end{tabular}




\section{Discussion}

Restoration of a neutral mechanical axis is essential for successful TKA $[27,28]$. Tibial components with a varus alignment over $3^{\circ}$ have a higher incidence of failure because of the increased stress on cancellous bone $[8,29]$ and increased proximal tibial strain, above the threshold for fatigue damage [30]. We previously performed a three-dimensional computer simulation to identify a reliable reference point for setting the guide [21]. In that study, we found that a line connecting the proximal and distal one-third of the anterior border was similarly parallel to the mechanical axis in the coronal plane. The results of this clinical study validate and enhance the importance of our computer simulation findings.

Several previous studies advocated the use of bony and soft tissue landmarks to identify the center of the ankle joint. These landmarks are easy to palpate, but their locations have varied widely among reports (for instance, the first and second metatarsal [20], a point 3-5 mm medial to the malleolar center [16,19], the extensor hallucis longus [18], and the tibialis anterior tendons [19]), and thus the most accurate location of the ankle joint center has remained controversial. In addition, soft tissue conditions, ankle deformities, and the direction of the surgeon's view all affect the localization of these distal landmarks. From the point of view of finding the most stable landmark for realizing the tibial mechanical axis, we advocate consideration of the line connecting the proximal and distal one-third of the anterior border of the tibia.

In this study, our first step was to determine the proximal tibial AP axis and then to align the guide to the anterior border while adjusting the rotational direction of the distal end of the guide to the AP axis of the proximal tibia. This method was based on the fact that rotational mismatch between the proximal part of the tibia and the ankle joint causes varus tibial cuts in TKA [26]. The ankle joint was found to be frequently externally rotated compared with the AP axis of the proximal part of the tibia [31], which caused the distal end of the extramedullary guide to be shifted laterally when placed in front of the center of the ankle joint in cases where the tibia was cut in varus. Sasanuma et al [32] conducted a clinical study examining the accuracy of cutting the proximal tibia using a line connecting the proximal and distal one-third of the anterior border of the tibia. They concluded that there was no difference in coronal alignment between the bony landmark method and the conventional method (within $3^{\circ}$ of the target angle: $84 \%$ vs. $88 \%$ ). However, the rotation of tibial cutting in their approach was parallel to the shaft of the second metatarsal, which should cause malalignment due to the rotational mismatch mentioned above. In fact, our study showed that the postoperative CTA exceeded $3^{\circ}$ on the mechanical axis in only $3.9 \%$ of cases, a significant difference compared with the conventional method. It is possible that bone cutting error occurred in this study, because the computer simulation showed correct alignment when using the anterior border of the tibia.

The current study has several limitations. First, it was retrospective in design. A randomized controlled study is optimal to test a hypothesis in a clinical setting, but in this case we could not perform a theoretically incorrect procedure on patients. Second, this study evaluated postoperative alignment on radiographs. Analysis using the three-dimensional model reconstructed from the CT scan would provide more accurate evaluation [33], but we paid meticulous attention to rotational direction while obtaining the radiographs so as to diminish errors in the evaluation of alignment. Third, this study included Asian patients with varus knees only. We should evaluate other ethnic groups with several knee deformities in the future. Fourth, we did not evaluate inter-observer and intra-observer error in identifying the proximal and distal onethird of the anterior border intraoperatively. It was difficult to find an adequate intraoperative measurement method that has been validated to accurately reflect reproducibility. Despite these limitations, our research demonstrated the accuracy of cutting proximal tibial bone during TKA using the anterior border of the tibia as a bony landmark.

In conclusion, we evaluated the effectiveness of using the anterior border of the tibia as a bony landmark during TKA in varus knees with osteoarthritis. Our study proved that the proximal one-third and the distal one-third of the anterior tibial border were reliable landmarks for the tibial extramedullary alignment guide in TKA in a clinical setting, supporting our previous computer simulation results.

\section{References}

1. Rodricks DJ, Patil S, Pulido P, et al. Press-fit condylar design total knee arthroplasty. Fourteen to seventeen-year follow-up. J Bone Joint Surg Am 2007;89:89.

2. Vessely MB, Whaley AL, Harmsen WS, et al. The Chitranjan Ranawat Award: longterm survivorship and failure modes of 1000 cemented condylar total knee arthroplasties. Clin Orthop Relat Res 2006;452:28.

3. Kim YH, Park JW, Kim JS, et al. The relationship between the survival of total knee arthroplasty and postoperative coronal, sagittal and rotational alignment of knee prosthesis. Int Orthop 2014;38:379.

4. Sikorski JM. Alignment in total knee replacement. J Bone Joint Surg (Br) 2008;90:1121.

5. Berger RA, Crossett LS, Jacobs JJ, et al. Malrotation causing patellofemoral complications after total knee arthroplasty. Clin Orthop Relat Res 1998;356:144.

6. Jeffery RS, Morris RW, Denham RA. Coronal alignment after total knee replacement. J Bone Joint Surg (Br) 1991;73:709.

7. Ritter MA, Faris PM, Keating EM, et al. Postoperative alignment of total knee replacement. Its effect on survival. Clin Orthop Relat Res 1994;299:153.

8. Berend ME, Ritter MA, Meding JB, et al. Tibial component failure mechanisms in total knee arthroplasty. Clin Orthop Relat Res 2004;428:26.

9. Teter KE, Bregman D, Colwell Jr CW. Accuracy of intramedullary versus extramedullary tibial alignment cutting systems in total knee arthroplasty. Clin Orthop Relat Res 1995;321:106.

10. Caillouette JT, Anzel SH. Fat embolism syndrome following the intramedullary alignment guide in total knee arthroplasty. Clin Orthop Relat Res 1990;251:198.

11. Kalairajah Y, Cossey AJ, Verrall GM, et al. Are systemic emboli reduced in computerassisted knee surgery? A prospective, randomised, clinical trial. J Bone Joint Surg (Br) 2006;88:198.

12. de Kroon KE, Houterman S, Janssen RP. Leg alignment and tibial slope after minimal invasive total knee arthroplasty: a prospective, randomized radiological study of intramedullary versus extramedullary tibial instrumentation. Knee 2012;19:270.

13. Reed MR, Bliss W, Sher JL, et al. Extramedullary or intramedullary tibial alignment guides: a randomised, prospective trial of radiological alignment. J Bone Joint Surg (Br) 2002;84:858.

14. Mahaluxmivala J, Bankes MJ, Nicolai P, et al. The effect of surgeon experience on component positioning in 673 Press Fit Condylar posterior cruciate-sacrificing total knee arthroplasties. J Arthroplasty 2001;16:635.

15. Petersen TL, Engh GA. Radiographic assessment of knee alignment after total knee arthroplasty. J Arthroplasty 1988;3:67.

16. Fang DM, Ritter MA, Davis KE. Coronal alignment in total knee arthroplasty: just how important is it? J Arthroplasty 2009;24:39.

17. Rajadhyaksha AD, Mehta H, Zelicof SB. Use of tibialis anterior tendon as distal landmark for extramedullary tibial alignment in total knee arthroplasty: an anatomical study. Am J Orthop (Belle Mead NJ) 2009;38:E68.

18. Schneider M, Heisel C, Aldinger PR, et al. Use of palpable tendons for extramedullary tibial alignment in total knee arthroplasty. Arthroplasty 2007;22:219.

19. Simmons Jr ED, Sullivan JA, Rackemann S, et al. The accuracy of tibial intramedullary alignment devices in total knee arthroplasty. J Arthroplasty 1991;6:45.

20. Tew M, Waugh W. Tibiofemoral alignment and the results of knee replacement. J Bone Joint Surg (Br) 1985;67:551.

21. Fukagawa S, Matsuda S, Mitsuyasu $\mathrm{H}$, et al. Anterior border of the tibia as a landmark for extramedullary alignment guide in total knee arthroplasty for varus knees. J Orthop Res 2011;29:919.

22. Mizu-uchi H, Matsuda S, Miura H, et al. The evaluation of post-operative alignment in total knee replacement using a CT-based navigation system. J Bone Joint Surg (Br) 2008;90:1025.

23. Berger RA, Rubash HE, Seel MJ, et al. Determining the rotational alignment of the femoral component in total knee arthroplasty using the epicondylar axis. Clin Orthop Relat Res 1993;286:40.

24. Kuwano T, Urabe K, Miura H, et al. Importance of the lateral anatomic tibial slope as a guide to the tibial cut in total knee arthroplasty in Japanese patients. J Orthop Sci 2005;10:42.

25. Matsui Y, Kadoya Y, Uehara K, et al. Rotational deformity in varus osteoarthritis of the knee: analysis with computed tomography. Clin Orthop Relat Res 2005;433:147.

26. Mizu-uchi $\mathrm{H}$, Matsuda S, Miura $\mathrm{H}$, et al. The effect of ankle rotation on cutting of the tibia in total knee arthroplasty. J Bone Joint Surg Am 2006;88:2632.

27. Lombardi Jr AV, Berend KR, Ng VY. Neutral mechanical alignment: a requirement for successful TKA: affirms. Orthopedics 2011;34:e504.

28. Green GV, Berend KR, Berend ME, et al. The effects of varus tibial alignment on proximal tibial surface strain in total knee arthroplasty: the posteromedial hot spot. J Arthroplasty 2002;17:1033.

29. Perillo-Marcone A, Taylor M. Effect of varus/valgus malalignment on bone strains in the proximal tibia after TKR: an explicit finite element study. J Biomech Eng 2007;129:1.

30. Wong J, Steklov N, Patil S, et al. Predicting the effect of tray malalignment on risk for bone damage and implant subsidence after total knee arthroplasty. J Orthop Res 2011;29:347.

31. Nagamine R, Miyanishi K, Miura H, et al. Medial torsion of the tibia in Japanese patients with osteoarthritis of the knee. Clin Orthop Relat Res 2003;408:218.

32. Sasanuma H, Sekiya H, Takatoku K, et al. Accuracy of a proximal tibial cutting method using the anterior tibial border in TKA. Eur J Orthop Surg Traumatol 2014;24:1525.

33. Mizu-uchi H, Matsuda S, Miura H, et al. Three-dimensional analysis of computed tomography-based navigation system for total knee arthroplasty: the accuracy of computed tomography-based navigation system. J Arthroplasty 2009;24:1103. 